\title{
PERANCANGAN MODEL SIMULASI SISTEM PENDETEKSI KEBOCORAN GAS DAN KEBAKARAN SEBAGAI MEDIA PEMBELAJARAN BERBASIS INTERNET OF THINGS (IOT)
}

\author{
Rahmad Hidayat ${ }^{1)}$, Yudi Herdiana ${ }^{2)}$ \\ 1) Teknik Elektro Sekolah Tinggi Teknologi Mandala \\ 2) Teknologi Informasi Universitas Bale Bandung \\ e-mail: rhidayat4000@gmail.com²),fti@unibba.ac.id ${ }^{2)}$
}

\begin{abstract}
ABSTRAK
Era revolusi industri 4.0 telah menghadirkan banyak percepatan terhadap perkembangan teknologi sehingga menjadi lebih mudah, cepat, dan praktis. Salah satu penerapan teknologi tersebut salah satunya dibidang pendidikan, berupa perancangan model simulasi alat pendeteksi kebocoran gas dan kebakaran sebagai media pendukung pembelajaran menggunakan modul mikrokontroler serta mengintegrasikannya ke dalam saluran komunikasi data internet agar siswa dapat melakukan pengujian dan pemantauan secara real time melalui perangkat mobile. Perancangan model simulasi ini menggunakan modul ESP8266, sensor DHT-11, dan sensor MQ-135. Untuk layanan cloud computing menggunakan database serta aplikasi Thingspeak. Metode yang digunakan pada perancangan ini berupa metode eksperimental. Metode ini banyak digunakan dalam perancangan sebuah sistem karena dapat menguji secara benar hipotesis yang menyangkut hubungan kasual. Berdasarkan hasil pengujian, sistem yang dibangun dapat berfungsi secara baik serta memberikan informasi mengenai nilai kondisi yang sedang diujikan. Siswa dapat memantau kondisi pengujian secara real time melalui aplikasi Thingspeak yang dipasangkan pada perangkat mobile.
\end{abstract}

Kata Kunci: Cloud Computing, Mikrokontroler, Mobile, Teknologi

\begin{abstract}
The era of the industrial revolution 4.0 has provided a lot of acceleration of technological developments so that it becomes easier, faster, and practical. One of the applications of this technology is in the field of education, in the form of designing simulation models for detection of gas leaks and fires as a learning support media using microcontroller modules and integrating them into internet data communication channels so students can conduct testing and monitoring in real-time through mobile devices. The design of this simulation model uses the ESP8266 module, the DHT-11 sensor, and the MQ-135 sensor. For cloud computing services using databases and Thingspeak applications. The method used in this design is an experimental method. This method is widely used in designing a system because it can correctly test hypotheses concerning casual relationships. Based on the test results, the system built can function properly and provides information about the value of the condition being tested. Students can monitor the testing conditions in real-time through the Thingspeak application that is installed on a mobile device.
\end{abstract}

Keywords: Cloud Computing, Microcontroller, Mobile, Technology

\section{PENDAhUluan}

$\mathrm{E}$ ra revolusi industri 4.0 telah menghadirkan banyak percepatan terhadap perkembangan teknologi sehingga menjadi lebih mudah, cepat, dan praktis. Salah satu penerapan teknologi tersebut salah satunya dibidang pendidikan, berupa perancangan model simulasi alat pendeteksi kebocoran gas dan kebakaran sebagai media pendukung pembelajaran. Kebakaran merupakan sebuah peristiwa terjadinya nyala api baik kecil maupun besar pada suatu tempat, situasi dan waktu yang tidak dikehendaki yang bersifat merugikan dan pada umumnya sulit untuk dikendalikan. Salah satu penyebab kebakaran adalah adanya kebocoran gas. Percikan api dapat timbul diakibatkan gas oksigen atau O2. Kepadatan tingkat kandungan oksigen dapat mempengaruhi munculnya potensi kebakaran. Semakin tinggi kandungan oksigen pada suatu titik atau ruang maka nyala api yang ditimbulkan akan semakin besar, namun potensi kebakaran akan semakin rendah bila tingkat kandungan oksigen pada suatu titik atau ruang berada dibawah kisaran $12 \%$.

Sebuah alat pendeteksi kebakaran (fire detector) merupakan sebuah perangkat yang berfungsi untuk mendeteksi sumber yang berpotensi mengakibatkan terjadinya kebakaran melalui adanya asap, suhu udara yang panas, serta nyala api. Fire detector [1]-[4] biasa ditempatkan dilokasi-lokasi tertentu dengan tujuan agar dapat mendeteksi secara dini kemungkinan terjadinya potensi kebakaran. Sistem pendeteksi kebakaran yang digunakan dilokasi tertentu seperti hotel, mall, bandara, biasanya sudah diintegrasikan dengan sistem pemadaman secara otomatis sehingga ketika ada sebuah parameter sinyal yang dapat memunculkan potensi kebakaran seperti asap, suhu udara 
yang panas, serta nyala api yang terdeteksi maka sistem pemadam berupa kran air akan otomatis terbuka dan alarm tanda bahaya akan dibunyikan sehingga setiap orang yang berada dilokasi tersebut dapat mengevakuasi diri.

Berdasarkan kondisi tersebut diatas, maka pengetahuan mengenai antisipasi potensi bahaya kebakaran harus dimiliki oleh setiap orang. Sebagai media bantu pembelajaran, pengetahuan, praktikum dan sosialisasi dilingkungan sekolah, sebuah model simulasi yang terdiri dari sebuah modul system control, sensor, serta aplikasi monitoring yang terhubung ke internet sehingga siswa dapat melakukan percobaan dan pengujian dan dapat mengaksesnya secara real time di mana saja melalui perangkat mobile yang terpasang aplikasi Thingspeak.

Pada [5], [6], informasi hasil pemrosesan nilai data oleh sistem pendeteksi kebocoran gas dan kebakaran dikirim melalui modem GSM dengan menggunakan metode sms gateway, yang mana sistem akan mengirimkan informasi berupa SMS ataupun telegram kepada pemilik rumah mengenai kondisi terkini yang dideteksi oleh sistem. Kemudian pada penelitian [7], informasi nilai data dimonitoring secara langsung menggunakan aplikasi desktop berbasis visual basic. Pengguna dapat melihat informasi kondisi status melalui aplikasi antarmuka pada layar monitor sehingga dapat dengan sigap mengantisipasi potensi bahaya kebakaran sesegera mungkin. Implementasi Internet of Things seperti pada [7]-[11], bertujuan untuk meningkatkan efisiensi dan efektifitas dalam hal monitoring serta pengawasan, karena akses dapat dilakukan secara mobile tanpa terkendala jarak dan tempat.

\section{TINJAUAN PUSTAKA}

\section{A. Arduino}

Arduino adalah mikrokontroller single-board yang bersifat open-source, menggunakan IC ATMega sebagai IC program dan softwarenya memiliki bahasa pemrograman yang sangat mirip dengan bahasa $C$, namun penulisannya mendekati bahasa manusia. Versi yang terakhir adalah Arduino Uno R3 (Revisi 3), menggunakan ATMEGA328 sebagai Microcontrollernya, memiliki 14 pin I/O digital dan 6 pin input analog.

\section{B. ESP8266}

ESP8266 merupakan modul wifi yang berfungsi sebagai perangkat tambahan mikrokontroler seperti Arduino agar dapat terhubung langsung dengan wifi dan membuat koneksi TCP/IP. Modul ini membutuhkan daya sekitar 3.3v dengan memiliki tiga mode wifi yaitu Station, Access Point dan Both (Keduanya). Modul ini juga dilengkapi dengan prosesor, memori dan GPIO dimana jumlah pin bergantung dengan jenis ESP8266 yang kita gunakan. Sehingga modul ini bisa berdiri sendiri tanpa menggunakan mikrokontroler apapun karena sudah memiliki perlengkapan layaknya mikrokontroler.

\section{Internet of Things}

Internet of Thing (IoT) adalah sebuah konsep dimana suatu objek yang memiliki kemampuan untuk mentransfer data melalui jaringan tanpa memerlukan interaksi manusia ke manusia atau manusia ke komputer. IoT telah berkembang dari konvergensi teknologi nirkabel, micro-electromechanical systems (MEMS), dan Internet.

\section{METODE PENELITIAN}

Metode yang digunakan pada perancangan ini berupa metode eksperimental. Metode ini banyak digunakan dalam perancangan sebuah sistem karena dapat menguji secara benar hipotesis yang menyangkut hubungan kasual. Pada perancangan model simulasi sistem pendeteksi kebocoran gas dan kebakaran ini dibangun menggunakan beberapa komponen perangkat diantaranya mikrokontroler Arduino, modul wifi ESP8266, sensor gas MQ-135, sensor suhu dan kelembaban DHT-11, serta buzzer alarm. Pemrograman dilakukan menggunakan Arduino IDE (Integrated Development Environment) yang sekaligus sebagai aplikasi antar muka dalam proses pengintegrasikan program perangkat lunak ke dalam perangkat arduino. Adapun rancangan skema desain model simulasi alat pendeteksi kebocoran gas dan kebakaran dapat dilihat seperti yang ditunjukan pada gambar 1 . 


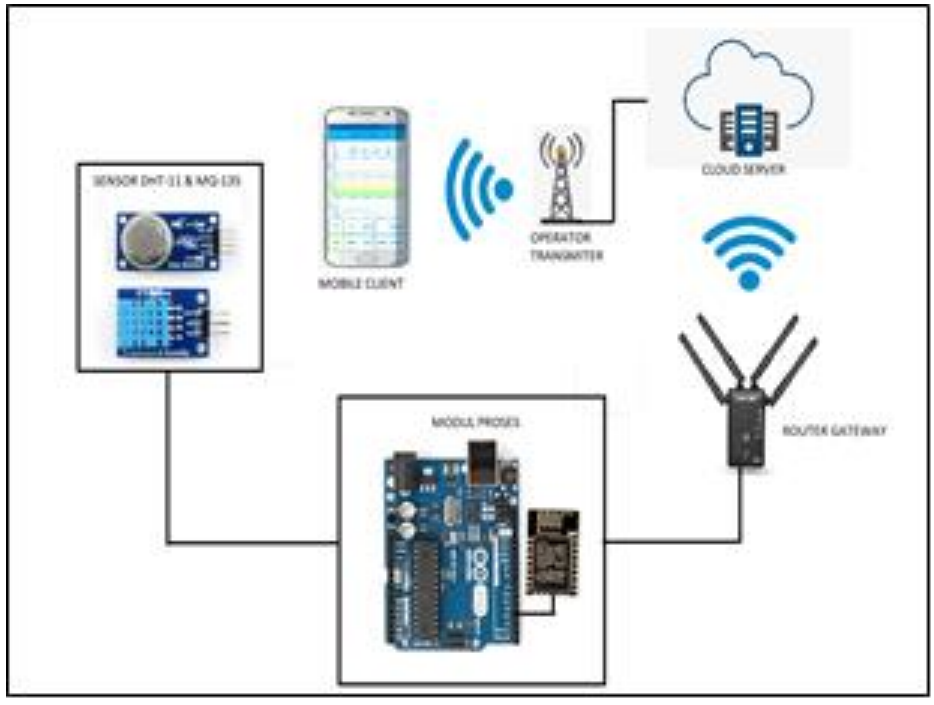

Gambar 1. Desain skema kerja sistem

Pada gambar diatas terlihat skema desain sistem model simulasi pendeteksi kebocoran gas dan kebakaran berbasis IoT. Pertama, sensor DHT-11 dan sensor MQ-135 akan menangkap sinyal analog dari suatu kondisi objek dan kemudian mentransmisikannya dalam bentuk digital untuk diproses oleh mikrokontroler. Hasil pemrosesan ini kemudian akan dikirimkan kedalam database cloud computing Thingspeak melalui saluran komunikasi data internet. Data ini kemudian disimpan dan selalu diupdate secara berkala demi terjaganya kualitas informasi data yang didapatkan, sehingga pengguna selalu menerima informasi secara real time selama terhubung.

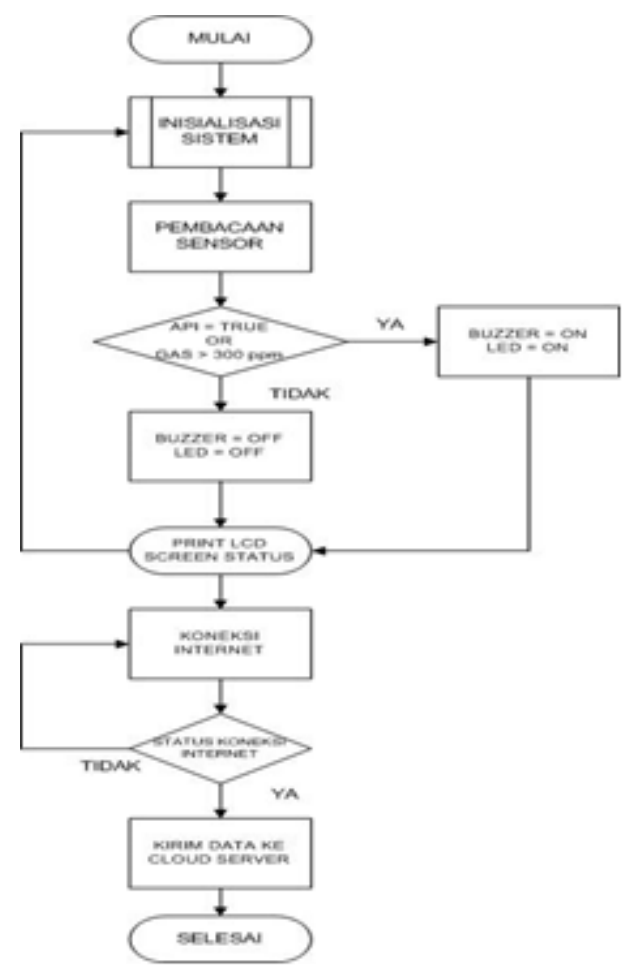

Gambar 2. Flowchart skema kerja sistem 


\section{A. Perancangan Perangkat Keras}

Perancangan perangkat keras pada penelitian ini meliputi perencanaan desain perangkat keras, konfigurasi, serta pengujian terhadap fungsi serta performa kerja alat.

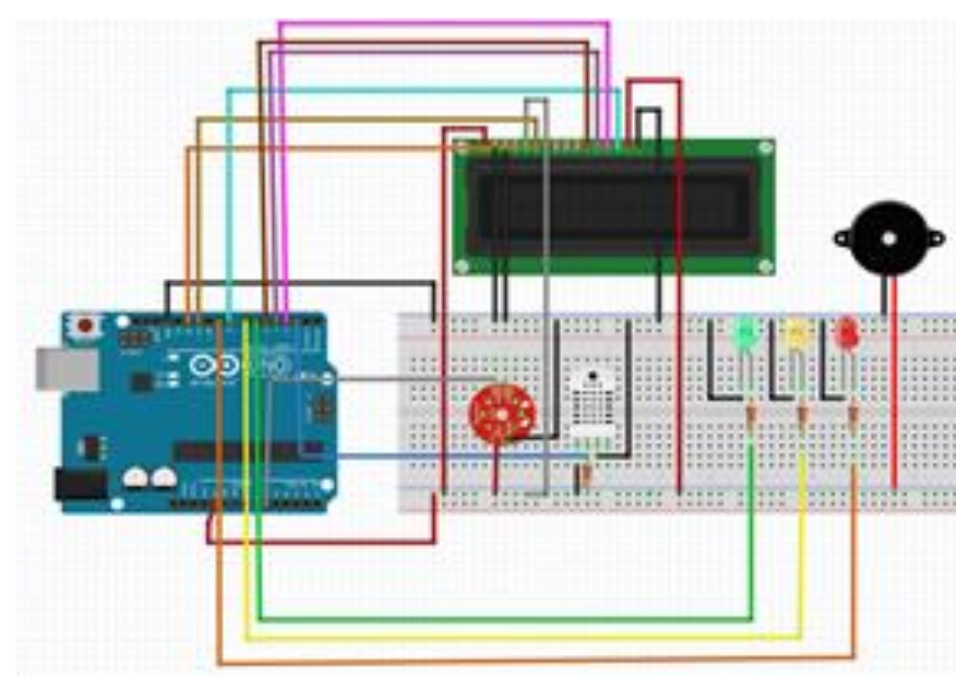

Gambar 3. Desain perangkat keras

Berdasarkan gambar 3, desain perangkat keras tersusun atas modul mikrokontroler Arduino sebagai pemroses data, sensor DHT-11 dan sensor MQ-135 sebagai pendeteksi kondisi objek yang diamati ( suhu, gas, dan kelembaban udara ). Buzzer sebagai tanda alarm peringatan bahaya, serta 3 buah LED ( merah, kuning, hijau ) sebagai indikator tingkat status kewaspadaan. Hasil pemrosesan data dari nilai yang diterima sensor kemudian akan dikirimkan ke database cloud computing Thingspeak dan juga akan ditampilkan melalui panel LCD screen.

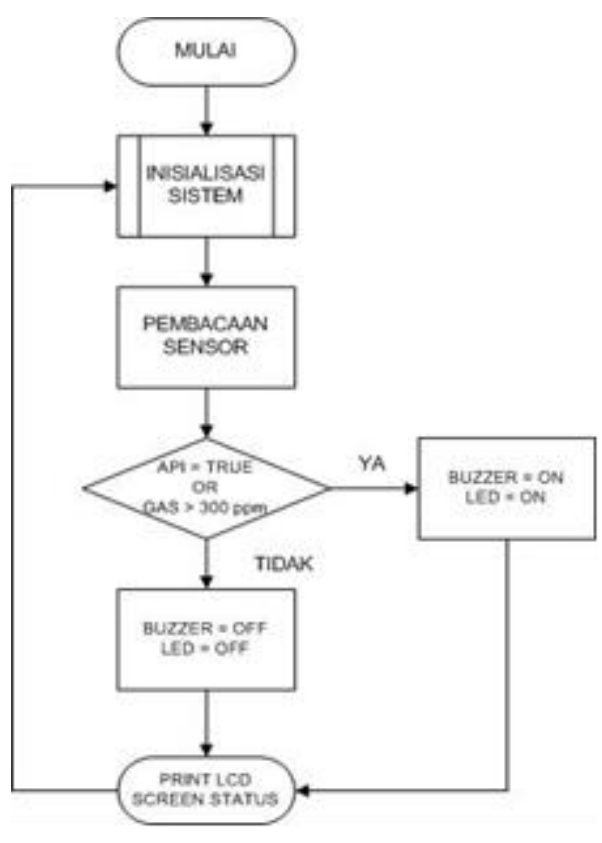

Gambar 4. Flowchart alur kerja perangkat keras

\section{B. Perancangan Perangkat Lunak}

Perancangan perangkat lunak menggunakan program Arduino IDE. Aplikasi ini digunakan untuk membuat list program berekstensi .ide serta bootloader Arduino yang digunakan untuk mengupload program kedalam perangkat mikrokontroler sehingga dapat berfungsi sessuai yang diprogramkan. 


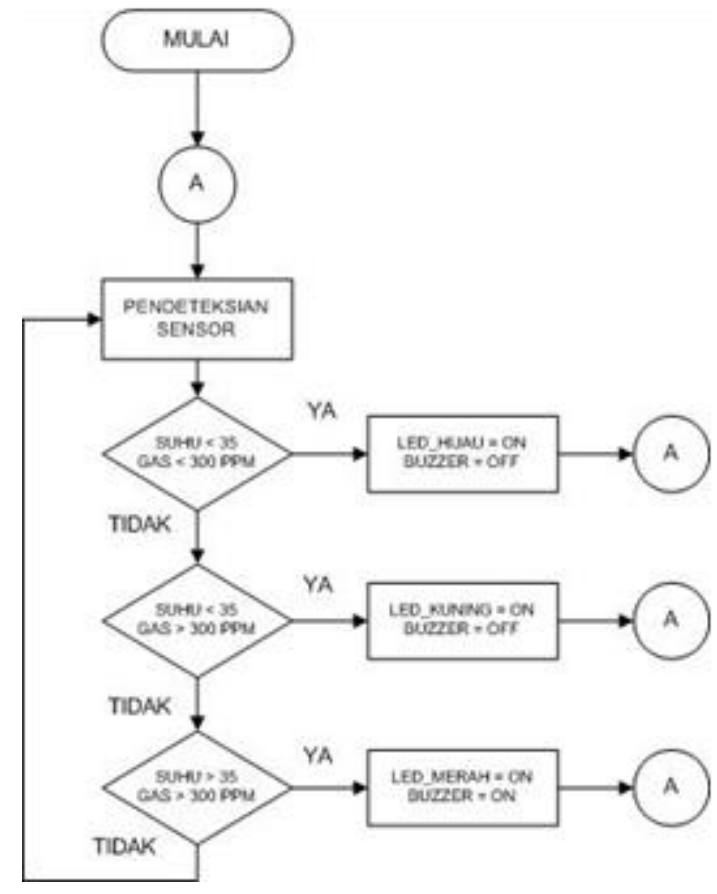

Gambar 5. Flowchart alur program perangkat lunak

Pada tahap awal program dibuat agar sistem mampu mendeteksi kondisi objek yang diteliti melalui sensor yang terpasang. Parameter yang ditetapkan untuk diintegrasikan pada sistem dapat dilihat pada table 1.

\begin{tabular}{|c|c|c|c|c|}
\hline \multirow[t]{2}{*}{ KONDISI STATUS } & \multicolumn{3}{|c|}{ INDIKATOR_LED } & \multirow{2}{*}{$\begin{array}{l}\text { BUZZER } \\
\text { STATUS }\end{array}$} \\
\hline & MERAH & KUNING & HIJAU & \\
\hline $\begin{array}{c}\text { SUHU }<35^{\circ} ; \text { GAS }< \\
300 \mathrm{ppm}\end{array}$ & OFF & OFF & ON & OFF \\
\hline $\begin{array}{l}\text { SUHU }<35^{\circ} ; \\
\text { GAS }>300 \text { ppm }\end{array}$ & OFF & ON & OFF & OFF \\
\hline $\begin{array}{c}\text { SUHU }>35^{\circ} ; \text { GAS }> \\
300 \mathrm{ppm}\end{array}$ & ON & OFF & OFF & ON \\
\hline
\end{tabular}

\section{HASIL DAN PEMBAHASAN}

Setelah proses perancangan model simulasi alat pendeteksi kebocoran gas dan kebakaran selesai dibangun, maka langkah berikutnya berupa pengujian terhadap kinerja dan performa perangkat. Adapun tahap pengujian yang dilakukan berupa test terhadap fungsi pendeteksian dari masing-masing sensor yang telah terpasang. Variasi pengujian berupa uji performa sensor pada rentang jarak dan waktu tertentu, kemudian dilakukan juga uji koneksi pada saat pengiriman data ke database cloud server Thingspeak. Pada pengujian tersebut akan nampak kualitas performa jaringan melalui waktu delay yang dibutuhkan pada saat pengiriman. data. Pada tahap selanjutnya, dilakukan proses pemantauan melalui aplikasi Thingspeak pada perangkat mobile siswa untuk melihat sejauh mana respon serta informasi yang dapat diterima. 


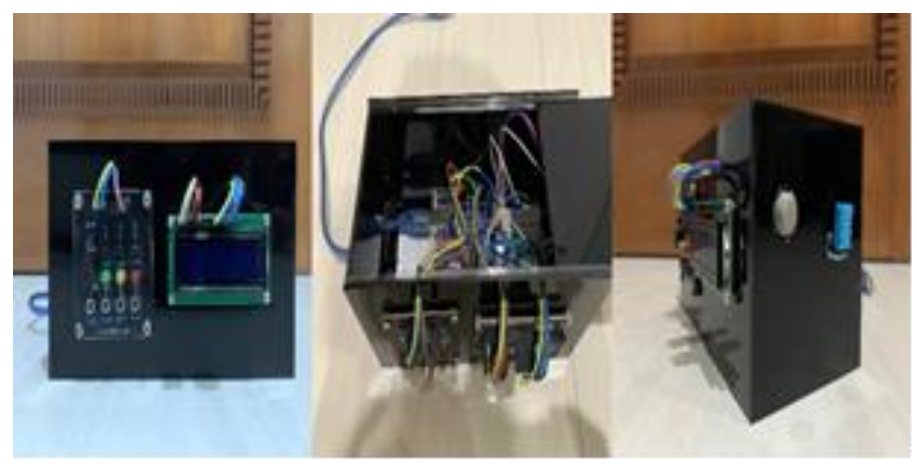

Gambar 6. Model simulasi alat pendeteksi gas dan kebakaran

\section{A. Pengujian sensor gas $M Q-135$}

Sensor MQ-135 diuji dengan cara diberikan rangsangan gas pada jarak tertentu:

Tabel 2. Tabel Pengujian Sensor Gas MQ-135

\begin{tabular}{cccc}
\hline $\begin{array}{c}\text { JARAK } \\
(\text { CM })\end{array}$ & $\begin{array}{c}\text { KUALITAS } \\
\text { UDARA }\end{array}$ & $\begin{array}{c}\text { INDIKATOR } \\
\text { SENSOR }\end{array}$ & $\begin{array}{c}\text { DELAY } \\
(\text { S })\end{array}$ \\
\hline 1 & 440 & BAHAYA & 1 \\
3 & 390 & BAHAYA & 7 \\
5 & 338 & BAHAYA & 9 \\
8 & 328 & BAHAYA & 12 \\
10 & 321 & BAHAYA & 15 \\
15 & 292 & AMAN & 18 \\
20 & 285 & AMAN & 24 \\
25 & 242 & AMAN & 26 \\
30 & 217 & AMAN & 29 \\
35 & 197 & AMAN & 31 \\
\hline
\end{tabular}

HASIL UI COBA SENSOR MQ-135 PADA JARAK BERBEDA

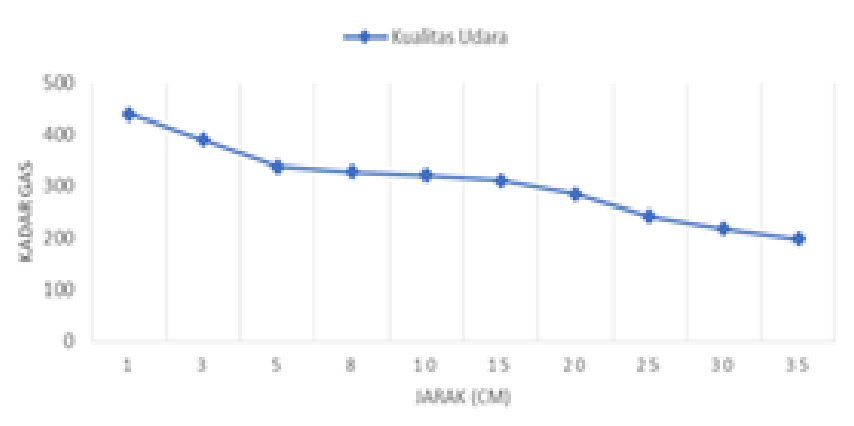

Gambar 7. Grafik hasil pengujian sensor gas MQ-135

Berdasarkan hasil pengujian yang dilakukan pada sensor MQ-135 dengan parameter jarak yang telah ditetapkan, terlihat bahwa rentang jarak yang berbeda sangat mempengaruhi proses pembacaan oleh sensor. Semakin jauh jarak, proses pembacaan oleh sensor menjadi semakin kurang presisi dan akurat dikarenakan delay waktu pembacaan yang terlalu lama. 
Hidayat dan Herdiana — Perancangan Model Simulasi Sistem Pendeteksi Kebocoran Gas dan Kebakaran sebagai Media Pembelajaran Media Pembelajaran berbasis IoT

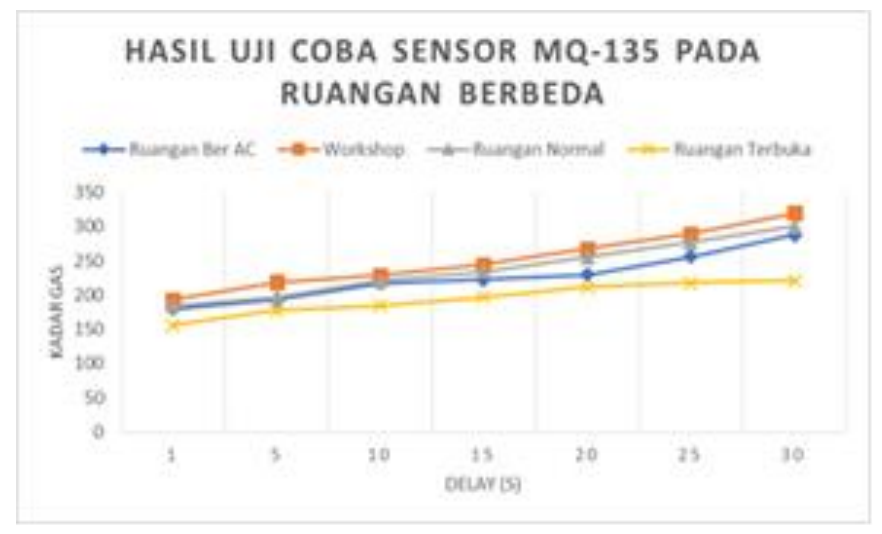

Gambar 8. Grafik hasil pengujian sensor gas MQ-135 pada kondisi ruang yang berbeda

Dari hasil pengujian sensor MQ-135 pada beberapa kondisi ruangan, dapat terlihat bahwa proses pembacaan data oleh sensor dipengaruhi oleh kondisi perputaran udara, kondisi tersebut mengakibatkan kondisi kebocoran gas sulit untuk dapat dibaca dengan cepat oleh sensor.

B. Pengujian sensor suhu DHT-11

Sensor DHT-11 diuji dengan cara diberikan rangsangan panas pada jarak tertentu

Tabel 3. Tabel Pengujian Sensor Gas MQ-135

\begin{tabular}{cccc}
$\begin{array}{c}\text { JARAK } \\
(\text { CM })\end{array}$ & $\begin{array}{c}\text { Tabel 3. Tabel Pengujian Sensor Gas MQ-135 } \\
\text { TEMPERATUR }\end{array}$ & $\begin{array}{c}\text { INDIKATOR } \\
\text { SENSOR }\end{array}$ & $\begin{array}{c}\text { DELAY } \\
(\text { S })\end{array}$ \\
\hline 1 & 85 & KEBAKARAN & 2 \\
3 & 82 & KEBAKARAN & 3 \\
5 & 79 & KEBAKARAN & 5 \\
8 & 77 & KEBAKARAN & 8 \\
10 & 53 & WASPADA & 12 \\
15 & 51 & WASPADA & 13 \\
20 & 48 & WASPADA & 16 \\
25 & 32 & AMAN & 19 \\
30 & 27 & AMAN & 23 \\
35 & 26 & AMAN & 27 \\
\hline
\end{tabular}

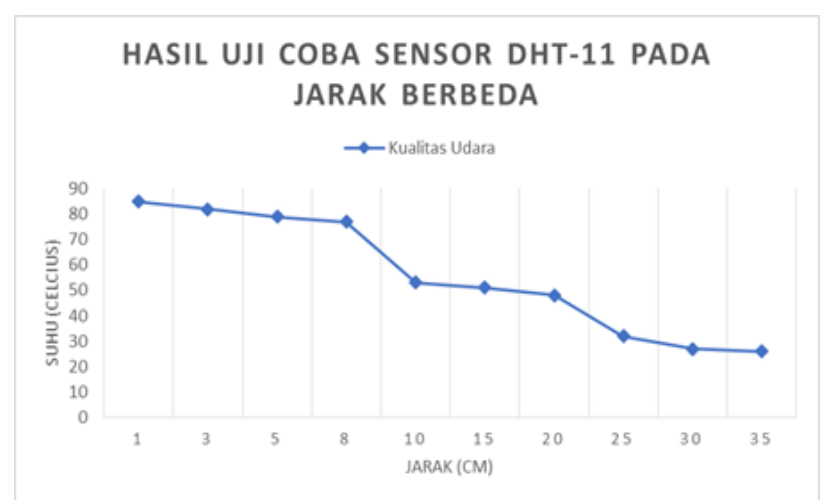

Gambar 9. Grafik hasil pengujian sensor suhu DHT-11 
Berdasarkan hasil pengujian pada sensor DHT-11 dengan berbagai Jarak, terlihat bahwa jarak yang berbeda sangat mempengaruhi proses pembacaan oleh sensor sehingga lokasi peletakan sensor dengan sumber gas. Semakin jauh jarak, sensor tidak dapat membaca suhu secara akurat dan presisi.

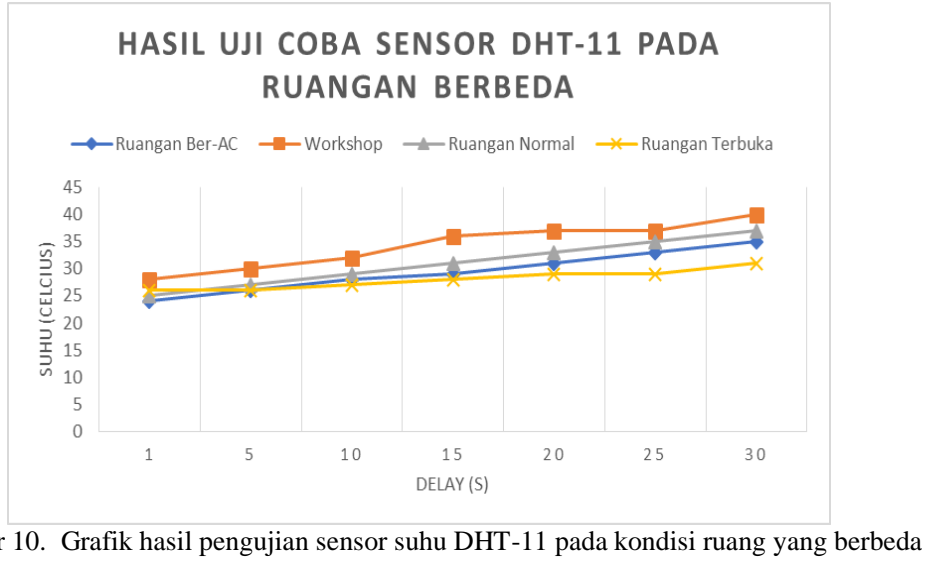

Dari hasil pengujian sensor DHT-11 pada berbagai kondisi ruangan, terlihat bahwa suhu yang terbaca pada sensor dipengaruhi oleh kepadatan udara pada ruangan tersebut yang mempengaruhi suhu awal pembacaan pada sensor. Pada ruangan kedap udara sensor akan lebih cepat membaca perubahan dibandingkan pada ruangn terbuka karena api pada ruangan terbuka mudah tertiup angin sehingga sensor sulit untuk membaca suhu.

\section{KESIMPULAN}

Perancangan model simulasi sistem pendeteksi kebocoran gas dan kebakaran yang dibangun dapat menunjukan performa serta kinerja yang baik. Hal ini dapat berdampak positif terhadap siswa yang memanfaatkan alat tersebut sebagai alat bantu penunjang proses pembelajaran. Namun, dikarenakan cloud server Thingspeak yang digunakan merupakan versi non-komersil, sehingga terdapat bebrapa pembatasan fasilitas yang salah satunya berupa delay pengiriman data per 15 detik, sehingga siswa tidak dapat melihat proses real time setiap detiknya. Namun secara keseluruhan hal tersebut sudah dapat memenuhi kebutuhan dasar sebagai media pembelajaran.

\section{DAFTAR PUSTAKA}

[1] J. Christian, "Prototipe Sistem Pendeteksi Kebocoran Gas LPG Menggunakan Sensor Gas MQ2, Board Arduino Duemilanove, Buzzer, dan Arduino GSM Shield pada PT. Alfa Retailindo (Carrefour Pasar Minggu)," J. TICom, vol. 2, no. 1, 2013.

[2] M. F. Putra, A. H. Kridalaksana, and Z. Arifin, "Rancang bangun alat pendeteksi kebocoran gas LPG dengan sensor MQ-6 berbasis mikrokontroler melalui smartphone android sebagai media informasi," 2017.

[3] W. Widyanto and D. Erlansyah, "Rancang Bangun Alat Deteksi Kebocoran Tabung Gas Elpiji Berbasis Arduino," Semantik, vol. 4, no. 1, 2014.

[4] D. D. Hutagalung, "Rancang bangun alat pendeteksi kebocoran gas dan api dengan menggunakan sensor MQ2 dan flame detector," J. Rekayasa Inf., vol. 7, no. 2, 2018.

[5] D. Nurnaningsih, "Pendeteksi kebocoran tabung LPG melalui SMS gateway menggunakan sensor MQ-2 berbasis Arduino Uno," J. Tek. Inform., vol. 11, no. 2, pp. 122-126, 2018.

[6] S. S. Dewi, D. Satria, E. Yusibani, and D. Sugiyanto, "Sistem Deteksi Kebakaran Pada Kasus Kebocoran Gas Berbasis Sms Gateway," in Prosiding Seminar Nasional USM, 2017, vol. 1, no. 1.

[7] Hidayat, Rahmad, et al. "Pendeteksi Kebocoran Gas Dan Kebakaran Berbasis Arduino Dengan Antarmuka Visual Basic." Smart Comp: Jurnalnya Orang Pintar Komputer 9.2 (2020): 76-79.

[8] Ramady, Givy Devira. "Perancangan Model Simulasi Sistem Pengendali Suhu Ruang Kelas Berbasis Internet Of Things." SENASTER" Seminar Nasional Riset Teknologi Terapan". Vol. 1. No. 1. 2020..

[9] Hidayat, Rahmad, et al. "Development of BTS Site Smart Key Based on Internet of Things." 2019 International Seminar on Application for Technology of Information and Communication (iSemantic). IEEE, 2019.

[10] S. C. Abadi, "Sistem Pemantauan Kualitas Udara Menggunakan Cloud Application Bluemix," J. Elektra, vol. 4, no. 2, pp. 38-43, 2019.

[11] Ramady, Givy Devira, et al. "Sistem Monitoring Data pada Smart Agriculture System Menggunakan Wireless Multisensor Berbasis IoT." Prosiding Seminar Nasional Teknoka. Vol. 4. 2019. 